\title{
Oxygen Wasting for $\mathrm{Ca}^{2+}$ Extrusion Activated by Partial Inhibition of Sarcoplasmic Reticulum $\mathrm{Ca}^{2+}$-ATPase by Cyclopiazonic Acid in Rat Left Ventricles
}

\author{
Hiromi MISAWA, Hisaharu KOHZUKI, Susumu SAKATA, \\ Yoshimi OHGA, and Miyako TAKAKI \\ Department of Physiology II, Nara Medical University, Kashihara, 634-8521 Japan
}

\begin{abstract}
In the excised Langendorff-perfused rat whole-heart preparation, a linear relation between left ventricular myocardial oxygen consumption per beat $\left(\mathrm{VO}_{2}\right)$ and systolic pressurevolume area (PVA, a total mechanical energy per beat) is obtained from a curved end-systolic pressure-volume relation as in the blood-perfused preparation. The ordinate $\mathrm{VO}_{2}$ intercept of the $\mathrm{VO}_{2}$-PVA relation is composed of $\mathrm{VO}_{2}$ for total $\mathrm{Ca}^{2+}$ handling in the excitation-contraction coupling and basal metabolism. The $\mathrm{VO}_{2}$ for total $\mathrm{Ca}^{2+}$ handling is mainly consumed by sarcoplasmic reticulum (SR) $\mathrm{Ca}^{2+}$-ATPase. The aim of the present study was to investigate, in terms of left ventricular mechanoenergetics, how an inhibition of SR $\mathrm{Ca}^{2+}$-ATPase by cyclopiazonic acid (CPA; $4 \mu \mathrm{mol} / l)$ affects $\mathrm{Ca}^{2+}$ handling mechanisms in the excised Langendorff-perfused rat wholeheart preparation. The short-term (for 3 to $6 \mathrm{~min}$ after onset of the infusion) CPA infusion de-
\end{abstract}

creased $\mathrm{VO}_{2}$ proportionally to the decrease in PVA. The long-term (for 9 to $12 \mathrm{~min}$ after the short-term CPA infusion) CPA infusion gradually increased $V_{2}$ almost to the control level with an increase in PVA. The increases in both $\mathrm{VO}_{2}$ and PVA during this infusion were completely abolished by a $\mathrm{Na}^{+} / \mathrm{Ca}^{2+}$ exchanger inhibitor, 3',4'dichlorobenzamil, indicating the contribution of $\mathrm{Na}^{+} / \mathrm{Ca}^{2+}$ exchanger to the increases in $\mathrm{VO}_{2}$ and PVA. The $\mathrm{O}_{2}$ cost of left ventricular contractility during the long-term CPA infusion was significantly higher than during the short-term CPA infusion. All these results suggest the possibility of the contribution of greater energy-wasting $\mathrm{Ca}^{2+}$ extrusion processes (such as $\mathrm{Na}^{+} / \mathrm{K}^{+}$-ATPase coupled to the $\mathrm{Na}^{+} / \mathrm{Ca}^{2+}$ exchanger; its stoichiometry is 1 ATP : $1 \mathrm{Ca}^{2+}$ ) to the larger oxygen cost of left ventricular contractility. [Japanese Journal of Physiology, 51, 99-108, 2001]

Key words: cyclopiazonic acid, $\mathrm{O}_{2}$ consumption, sarcolemmal $\mathrm{Na}^{+} / \mathrm{Ca}^{2+}$ exchanger, sarcoplasmic reticulum $\mathrm{Ca}^{2+}$-ATPase.

$\mathrm{W}_{\mathrm{e}}$ myocardial oxygen consumption per beat $\left(\mathrm{VO}_{2}\right)$ and systolic pressure-volume area (PVA; a total mechanical energy per beat) [1-3] from the curved end-systolic pressure-volume relation (ESPVR) [1-4] in the rat whole-heart preparation. End-systolic pressure $\left(\mathrm{ESP}_{\mathrm{mLVV}}\right)$ and pressure-volume area $\left(\mathrm{PVA}_{\mathrm{mLVV}}\right)$ at a midrange left ventricular volume (mLVV) represent left ventricular contractility and total mechanical energy of an isovolumic contraction at the mLVV. Thus we have proposed $\mathrm{PVA}_{\mathrm{mLVV}}$ to quantify and compare left ventricular mechanoenergetics [1-3]. The ordinate intercept of the linear $\mathrm{VO}_{2}$-PVA relation is mainly composed of $\mathrm{VO}_{2}$ for the total $\mathrm{Ca}^{2+}$ handling in the

Received on October 16, 2000; accepted on December 15, 2000

Correspondence should be addressed to: Miyako Takaki, Department of Physiology II, Nara Medical University, 840 Shijo-cho, Kashihara, 634-8521 Japan. Tel: +81-744-29-8829, Fax: +81-744-23-4696, E-mail: mtakaki@naramed-u.ac.jp

Abbreviations: CPA, cyclopiazonic acid; DCB, 3',4'-dichlorobenzamil; EDPVR, end-diastolic pressure-volume relation; ESPVR, end-systolic pressure-volume relation; ino-run, inotropism run; LT, long-term; mLVV, midrange left ventricular volume; PVA, pressure-volume area; SR, sarcoplasmic reticulum; ST, short-term; $V_{2}$, myocardial oxygen consumption per beat; volume run, volume loading run; (eESP/ESV) $\mathrm{mLVv}$, an equivalent end-systolic pressure-volume ratio at a mLVV; eEmax, equivalent maximal elastance. 
excitation-contraction coupling and basal metabolism $[1-3,5]$.

We have investigated the fraction of energy expenditure used for the sarcoplasmic reticulum (SR) $\mathrm{Ca}^{2+}$ ATPase in $\mathrm{VO}_{2}$ for the total $\mathrm{Ca}^{2+}$ handling by using thapsigargin [3]. However, thapsigargin $(2.5 \mu \mathrm{mol} / l)$ maximally decreased $\mathrm{VO}_{2}$ for the total $\mathrm{Ca}^{2+}$ handling by only $40 \%$, probably because of its low permeability to the cell [3]. We have therefore not fully investigated the fraction of energy expenditure used for the SR $\mathrm{Ca}^{2+}$-ATPase in the total $\mathrm{Ca}^{2+}$ handling $\mathrm{VO}_{2}$ in the rat whole-heart preparation.

On the other hand, we have already reported that the blockade of SR $\mathrm{Ca}^{2+}$-ATPase by cyclopiazonic acid (CPA; $1-10 \mu \mathrm{mol} / l)$ decreases the oxygen consumption for total $\mathrm{Ca}^{2+}$ handling in the excitationcontraction coupling by $70 \%$ in mechanically unloaded myocardial slices, whereas thapsigargin decreased it by only $40 \%$ at maximum [6]. The $70 \%$ reduction in the oxygen consumption by CPA corresponds to internal $\mathrm{Ca}^{2+}$ recirculation fraction via SR $\mathrm{Ca}^{2+}$-ATPase $(=0.8)$ estimated by the decay of twitch after the resting period in rat right ventricular trabeculae $[7,8]$.

In the excitation-contraction coupling of myocardium, the major source of $\mathrm{Ca}^{2+}$ that activates contraction is an internal store, SR. An important factor that controls the amount of $\mathrm{Ca}^{2+}$ released from the SR is its $\mathrm{Ca}^{2+}$ contents [9]. Nevertheless, the inotropic effect of even a simple maneuver such as the application of a high dose of caffeine (which directly affects the ryanodine receptor on SR) is complex. Such an effect depends on a combination of $\mathrm{Ca}^{2+}$ uptake and release by $\mathrm{SR}, \mathrm{Ca}^{2+}$ extrusion via sarcolemma, and cytosolic $\mathrm{Ca}^{2+}$ buffering action [10]. It is interesting to investigate how the application of low concentration of CPA, which can partially inhibit SR $\mathrm{Ca}^{2+}$-ATPase, affects $\mathrm{Ca}^{2+}$ handling mechanisms in terms of left ventricular mechanoenergetics.

The aim of the present study was to investigate how a partial inhibition of SR $\mathrm{Ca}^{2+}$-ATPase by CPA [11] affects left ventricular $\mathrm{VO}_{2}$ for total $\mathrm{Ca}^{2+}$ handling in the excitation-contraction coupling and oxygen cost of left ventricular contractility in the excised Tyrode-perfused rat heart. The partial inhibition of SR $\mathrm{Ca}^{2+}$-ATPase would alter $\mathrm{VO}_{2}$ for the total $\mathrm{Ca}^{2+}$ handling, i.e., the balance between "internal" $\mathrm{Ca}^{2+}$ uptake and "external" $\mathrm{Ca}^{2+}$ extrusion. The former energy expenditure is CPA-sensitive. The energy expenditure for external $\mathrm{Ca}^{2+}$ extrusion by $\mathrm{Na}^{+} / \mathrm{K}^{+}$-ATPase coupled to the $\mathrm{Na}^{+} / \mathrm{Ca}^{2+}$ exchanger is sensitive to a blocker of $\mathrm{Na}^{+} / \mathrm{Ca}^{2+}$ exchanger, 3',4'-dichlorobenzamil (DCB) $[12,13]$. DCB is one of most active inhibitors of
$\mathrm{Na}^{+} / \mathrm{Ca}^{2+}$ exchanger $[12,13]$. Present results suggested that a partial inhibition of SR $\mathrm{Ca}^{2+}$-ATPase by CPA increased external $\mathrm{Ca}^{2+}$ extrusion in the left ventricle of rat whole heart preparation.

\section{MATERIALS AND METHODS}

Care and experiments on all rats used in the present study were carried out under the Guiding Principles for the Care and Use of Animals in the Field of Physiological Sciences by the Council of the Physiological Society of Japan.

Twenty-five retired Wistar rats weighing $580 \pm 61 \mathrm{~g}$ were anesthetized with pentobarbital sodium (50 $\mathrm{mg} / \mathrm{kg}$, I.P.) and heparinized (1,000 U, I.V.). The whole-heart preparation was perfused by the Langendorff method [14]. Coronary flow rate was adjusted and kept constant at a perfusion pressure of $\sim 60$ $\mathrm{mmHg}$ throughout the control experiment, and it was kept constant throughout the CPA experiment by changing an infusion rate of a pump. Coronary perfusion pressure was measured continuously and divided by mean coronary flow rate to obtain coronary vascular resistance.

In the excised beating heart maintained at $37^{\circ} \mathrm{C}$, a thin latex balloon (balloon material volume, $0.08 \mathrm{ml}$ ) was inserted into the left ventricle and primed with water. It was connected to a pressure transducer (Life Kit DX-312, Nihon Kohden, Tokyo, Japan). The balloon water volume was changed with a $0.5 \mathrm{ml}$ precision glass syringe (minimum scale: $0.005 \mathrm{ml}$ ). The balloon developed no pressure and thus was unstretched as long as its volume was below approximately $0.25-0.3 \mathrm{ml}$. Therefore left ventricular volume was changed and measured by adjusting the intraballoon water volume with the syringe in $0.05 \mathrm{ml}$ steps from 0.08 to $0.28 \mathrm{ml}$. By sucking the water in the balloon completely, systolic unstressed volume $\left(V_{0}\right)$ should be determined as the volume at which peak isovolumic pressure and then PVA were zero. The systolic unstressed volume corresponds to $0.08 \mathrm{ml}$ (balloon material volume). Electrical pacing of the right atrium was performed at $250 \pm 50$ beats $/ \mathrm{min}$.

Data analysis. We attempted to fit experimentally obtained left ventricular pressure-volume data to the exponential equations to obtain ESPVRs and enddiastolic pressure-volume relations (EDPVRs); we then determined PVA by the same method as described previously [1-4]. The area under the best-fit EDPVR was subtracted from the area under the bestfit ESPVR to obtain the net PVA [1-4].

Oxygen consumption. $\quad \mathrm{VO}_{2}$ was calculated as the product of the coronary flow and arterio-venous 
oxygen content difference per pacing rate [1-3]. The total coronary flow was measured with an electromagnetic flowmeter in the coronary venous drainage tubing from the right ventricle [1-3]. To estimate oxygen contents, we measured arterial and venous oxygen partial pressure $\left(\mathrm{PO}_{2}\right)$ by using a blood gas analyzer (Radiometer ABL 330, Copenhagen, Denmark), and monitored continuously venous $\mathrm{PO}_{2}$ with an oxygen electrode (1T-125; Instech Labs, Plymouth Meeting, PA). Oxygen content was calculated as a product of solubility coefficient $\left(0.0031 \mathrm{vol} \% \mathrm{O}_{2} / \mathrm{mmHg}\right)$ [15] and $\mathrm{PO}_{2}$. As shown previously [1-3], the $\mathrm{VO}_{2}$-PVA relation was linear in the rat left ventricle.The $\mathrm{VO}_{2}$ intercept represents PVA-independent $\mathrm{VO}_{2}$. The right ventricle was kept collapsed by continuous hydrostatic drainage of the coronary venous return, so that the right ventricle PVA and thus the PVA-dependent $\mathrm{VO}_{2}$ were assumed to be negligible. The right ventricular component of PVA-independent $V \mathrm{O}_{2}$ was calculated by multiplying biventricular PVA-independent $\mathrm{VO}_{2}$ in each contractile state with the ratio of right ventricular weight divided by the sum of right ventricular and left ventricular weights. The right ventricular PVA-independent $V_{\mathrm{O}_{2}}$ was subtracted from the total $V_{\mathrm{O}_{2}}$ to yield left ventricular $\mathrm{VO}_{2}$. At the end of the experiment, the left ventricle, including the septum, and the right ventricular free walls were separately weighed. The left ventricular and right ventricular weights were
$1.28 \pm 0.12$ and $0.31 \pm 0.05 \mathrm{~g}(n=25)$. These left ventricular values were used for normalizing left ventricular volume.

\section{Experimental protocols (Fig. 1).}

Protocol $1(n=6)$. After the control different volume loading run (volume run), CPA inotropism run (ino-run) at an mLVV was performed during the infusion of $0.12 \mathrm{mmol} / l \mathrm{CPA}$ at a rate of $20 \mathrm{ml} / \mathrm{h}$ (final concentration; $4 \mu \mathrm{mol} / l$ ) in 6 hearts. During the CPA infusion, the initial decreases in $\mathrm{VO}_{2}$-PVA data were observed for 3 to $6 \mathrm{~min}$, and the following increases in $\mathrm{VO}_{2}$-PVA data were observed for 9 to $21 \mathrm{~min}$. We retrospectively defined the former period "ST CPA" and the latter period "LT CPA." CPA volume run at the same left ventricular volumes as in the control volume run was then performed during CPA infusion for a further 15 min after the CPA ino-run in five out of six hearts. Under left ventricular unloading condition, basal metabolism was then measured by $\mathrm{KCl}$-induced cardiac arrest for 3 min during CPA infusion and after washout of CPA in the same five hearts.

Protocol $2(n=6)$. After the control volume run, $\mathrm{Ca}^{2+}$ ino-run at an mLVV was performed during intracoronary infusion of $0.5 \% \mathrm{CaCl}_{2}$ solution at 8 to $25 \mathrm{ml} / \mathrm{h}$.

Protocol $3(n=6)$. After the control volume run and the CPA ino-run were performed, DCB $(5 \mu \mathrm{mol} / l)$ was simultaneously infused with CPA for a further

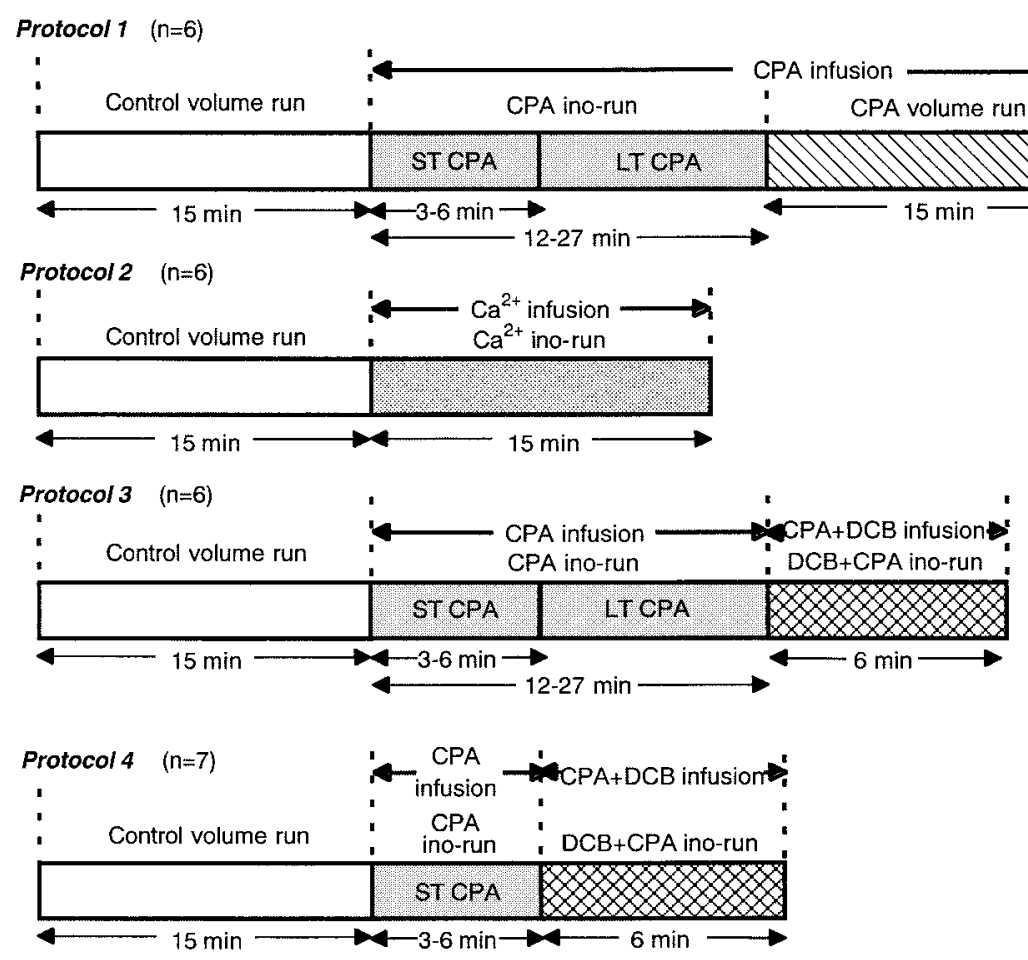

Fig. 1. Protocols 1-4. ST CPA, short-term cyclopiazonic acid (CPA, $4 \mu \mathrm{mol} / /$ ) infusion (for 3 to 6 min after onset of the infusion); LT CPA, long-term CPA infusion (for 9 to 21 min after the ST CPA infusion); DCB, 3', 4'-dichlorobenzamil (5 $\mu$ mol/l). See text for detailed explanation for protocols. 


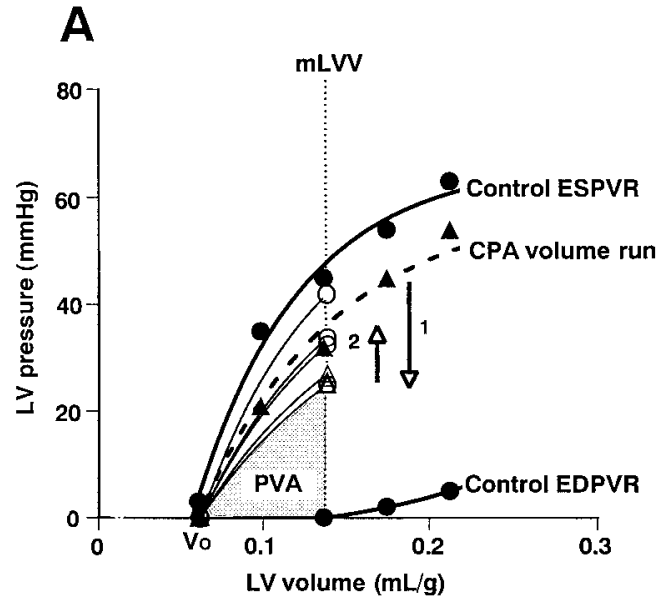

Fig. 2. Effects of short-term (ST) and long-term (LT) cyclopiazonic acid (CPA, $4 \mathrm{mmol} /$ ) infusion on left ventricular (LV) end-systolic pressure-volume relation (ESPVR) and end-diastolic pressure-volume relation (EDPVR) (A) and myocardial oxygen consumption per beat $\left(\mathrm{VO}_{2}\right)$ and systolic pressure-volume area (PVA) relation (B) in one Langendorff-perfused rat heart. A: ESP at a mid-range $\mathrm{LV}$ volume $(\mathrm{mLVV})$ of $0.14 \mathrm{ml} / \mathrm{g}$ decreased during the ST CPA infusion (1; open circles), then increased during the LT CPA infusion (2; open triangles). The dotted

6 min and the "DCB $+\mathrm{CPA}$ " ino-run was performed.

Protocol $4(n=7)$. After the control volume run and the CPA ino-run were performed, DCB $(5 \mu \mathrm{mol} / l)$ was simultaneously infused with CPA for a further 6 min after the ST CPA infusion, and "DCB + CPA" ino-run was performed.

PVA-independent $\mathrm{VO}_{2}$. We first obtained control ESPVR from the observed end-systolic pressurevolume data at five or six different left ventricular volumes as a best-fit exponential function curve (Table 1). During $\mathrm{Ca}^{2+}$ or CPA ino-run at an mLVV, end-systolic pressure-volume and $\mathrm{VO}_{2}$ data were sampled. We then obtained each ESPVR as a best-fit curve to the observed end-systolic pressure-volume data and those at systolic unstressed volume $\left(V_{0}\right)$. We calculated PVA by integrating each ESPVR from $V_{0}$ to the mLVV [1-4]. An example was shown in Fig. 2A. Each corresponding PVA increased as each end-systolic pressure increased under an isovolumic contraction.

We then obtained the composite $\mathrm{VO}_{2}$-PVA relations at the mLVV during stepwise increased $\mathrm{Ca}^{2+}$ or CPA infusion as the example shows in Fig. 2B. The slope of the $\mathrm{VO}_{2}$-PVA relation during $\mathrm{CPA}$ volume run did not differ from that of the control $\mathrm{VO}_{2}-\mathrm{PVA}$ relation (Fig. 2B). From this result, we assumed that every $V_{\mathrm{O}_{2}}$-PVA relation, including all $\mathrm{VO}_{2}-\mathrm{PVA}$ data, during the CPA ino-run at the mLVV would be parallel to the control $\mathrm{VO}_{2}$-PVA relation line (Fig. 2B). The $\mathrm{VO}_{2}$-intercept values that decreased or increased (PVA-inde-
B Control volume run

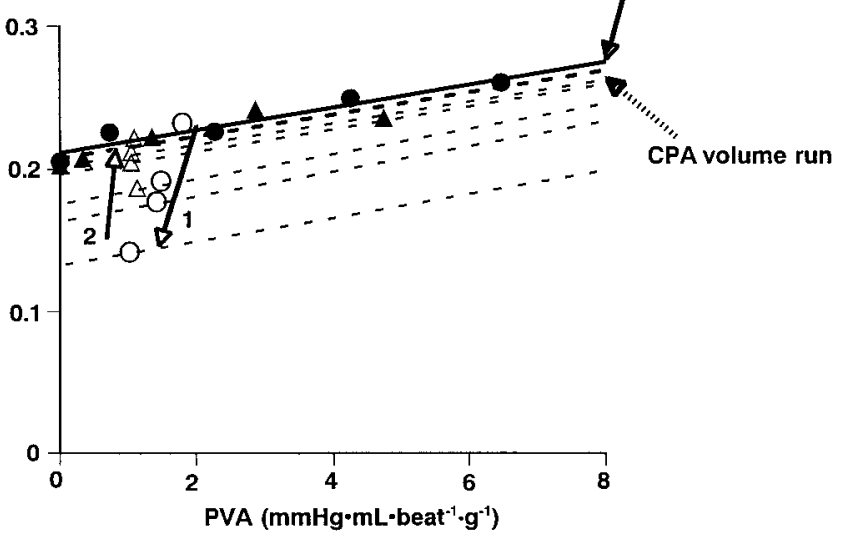

ESPVR (solid triangles) was obtained by a different volume loading run during CPA infusion (CPA volume run) after the LT CPA infusion (protocol 1). B: The control $V_{O_{2}}-P V A$ relation (solid circles) was obtained by a different volume loading run (control volume run). $\mathrm{VO}_{2}$-PVA data points at an $\mathrm{mLVV}$ of $0.14 \mathrm{ml} / \mathrm{g}$ decreased during the ST CPA infusion (1; open circles), then increased during the LT CPA infusion (2; open triangles). The dotted $V_{2}$ - PVA relation in CPA volume run (solid triangles) was obtained during CPA infusion after the LT CPA infusion (protocol 1).

pendent $\mathrm{VO}_{2}$ values) proportionally to the depressed or enhanced left ventricular contractility by CPA were obtained by this procedure [2]. Basal metabolic $\mathrm{VO}_{2}$ was unaltered during the $\mathrm{Ca}^{2+}$ (our unpublished observations) or CPA infusion (our present results), thus indicating that the increased PVA-independent $\mathrm{VO}_{2}$ values are due to the increased $\mathrm{VO}_{2}$ for $\mathrm{Ca}^{2+}$ handling in the excitation-contraction coupling.

LV contractility. As an index for LV contractility, we have proposed an "equivalent" end-systolic pressure-volume ratio at a $\mathrm{mLVV},(\mathrm{eESP} / \mathrm{ESV})_{\mathrm{mLV}}$ [2]. We here redefined it as eEmax (equivalent maximal elastance). This index is obtained by calculating end-systolic pressure-volume ratio of the specific virtual triangular $\mathrm{PVA}_{\mathrm{mLVV}}$ that is energetically equivalent to the real $\mathrm{PVA}_{\mathrm{mLVV}}[2]$. $\mathrm{PVA}_{\mathrm{mLVV}}$ has been proposed to be a good index for evaluating rat left ventricular contractility in terms of mechanoenergetics [1-4].

Oxygen cost of left ventricular contractility. Plots of PVA-independent $\mathrm{VO}_{2}$ and eEmax data gave us the linear relation between them (Fig. 4A). The oxygen cost of left ventricular contractility was obtained as the slope of this relation. This slope is an index quantifying $\mathrm{VO}_{2}$ for $\mathrm{Ca}^{2+}$ handling in the excitation-contraction coupling per unit left ventricular contractility change by CPA or $\mathrm{Ca}^{2+}$.

Drug. CPA and DCB were dissolved in dimethylsulfoxide (DMSO), then diluted to the appro- 
priate concentration with Tyrode solution (final concentration of DMSO; less than $0.1 \%$ ).

Statistics. All data were presented as mean \pm SD. Multiple comparisons were performed by repeated-measures analysis of variance and Bonferroni's method. Paired and nonpaired data were compared by the paired and nonpaired $t$-test, respectively. In all statistical tests, $p$ values less than 0.05 were considered statistically significant.

\section{RESULTS}

In the present study, a reasonably linear relation was found between $V_{2}$ and PVA from the curved ESPVR; $V \mathrm{O}_{2}$ increased in steps with increased PVA. The mean slope of the $\mathrm{VO}_{2}$-PVA relation was $0.011 \pm 0.004 \mu \mathrm{l}$ $\mathrm{O}_{2} \cdot \mathrm{mmHg}^{-1} \cdot \mathrm{ml}^{-1}$, and its mean $\mathrm{VO}_{2}$ intercept (PVAindependent $\mathrm{VO}_{2}$ ) was $0.27 \pm 0.05 \mu \mathrm{O}_{2} \cdot$ beat $^{-1} \cdot \mathrm{g}^{-1}$ in 12 Langendorff-perfused rat hearts under the constant perfusion rate (Table 1).

\section{Time courses of $\mathrm{VO}_{2}-\mathrm{PVA}_{\mathrm{mLVv}}$ data during the ST and LT CPA infusion}

Figure 2 shows left ventricular mechanical and energetic data in the control volume run, CPA ino-run at a mLVV during the ST and LT CPA infusion, and CPA volume run after the infusion (protocol 1). Data sampling was started 3 min after the onset of drug infusion. In each volume, a steady state was reached 3 min after changing the left ventricular volume. The arrows in Fig. 2 show the time courses of $\mathrm{ESP}_{\mathrm{mLVV}}$ (A) and $\mathrm{VO}_{2}-\mathrm{PVA}_{\mathrm{mLVV}}$ data (B) during the ST (1) and LT CPA infusion (2). During the ST CPA infusion (1), $\mathrm{ESP}_{\mathrm{mLVV}}$ was decreased (Fig. 2A), and thus $\mathrm{PVA}_{\mathrm{mLVV}}$ and $\mathrm{VO}_{2}$ were decreased (Fig. 2B). During the LT CPA infusion (2), $\mathrm{ESP}_{\mathrm{mLVV}}$ was increased (Fig. 2A), and thus $\mathrm{PVA}_{\mathrm{mLVV}}$ and $\mathrm{OO}_{2}$ were increased (Fig. 2B). $\mathrm{VO}_{2}$ was increased to the control level, but $\mathrm{ESP}_{\mathrm{mLVV}}$ and $\mathrm{PVA}_{\mathrm{mLVV}}$ remained decreased from the control. Neither the slope nor the $\mathrm{VO}_{2}$ intercept of $\mathrm{VO}_{2}$-PVA relation showed significant differences between control and CPA volume runs by an analysis of covariance in this heart (Fig. 2B). The other two hearts showed similar results, though in the remaining two hearts $\mathrm{VO}_{2}-$ intercept values were significantly different from those in the control by an analysis of covariance. The summarized data of five hearts were shown in Table 1. Neither the mean slope nor the mean $V_{\mathrm{O}_{2}}$ intercept of $\mathrm{VO}_{2}$-PVA relations showed significant differences between control and CPA volume runs by the paired $t$ test $(n=5)$ and unpaired $t$-test (Table 1$)$.
Table 1. Variables of left ventricular mechanoenergetics and hemodynamics in the control $(n=12)$ and cyclopiazonic acid (CPA)-infused hearts $(n=5)$.

\begin{tabular}{|c|c|c|}
\hline & \multicolumn{2}{|c|}{$\begin{array}{c}\text { End-systolic pressure-volume } \\
\text { relation }\end{array}$} \\
\hline & Control & CPA \\
\hline$A(\mathrm{mmHg})$ & $79.7 \pm 15.2$ & $74.1 \pm 11.2$ \\
\hline$B(1 / \mathrm{ml})$ & $17.5 \pm 5.0$ & $10.8 \pm 3.4^{*}$ \\
\hline$V_{0}(\mathrm{ml} / \mathrm{g})$ & $0.06 \pm 0.01$ & $0.06 \pm 0.01$ \\
\hline $\begin{array}{l}\text { PVA }_{m L V V} \\
\left(\mathrm{mmHg} \cdot \mathrm{ml} \cdot \text { beat }^{-1} \cdot \mathrm{g}^{-1}\right)\end{array}$ & $2.85 \pm 0.87$ & $2.05 \pm 0.80$ \\
\hline$R$ & $0.995 \pm 0.004$ & $0.998 \pm 0.001$ \\
\hline
\end{tabular}

$\mathrm{VO}_{2}-\mathrm{PVA}$ relation

\begin{tabular}{|c|c|c|}
\hline & \\
\hline & Control & CPA \\
\hline \multicolumn{3}{|l|}{ Slope } \\
\hline$\left(\times 10^{-2} \mu \mathrm{l} \mathrm{O} 2 \cdot \mathrm{mmHg}^{-1} \cdot \mathrm{ml}^{-1}\right)$ & 1) $1.09 \pm 0.42$ & $1.01 \pm 0.02$ \\
\hline $\begin{array}{l}\mathrm{VO}_{2} \text { intercept } \\
\quad\left(\mu \mathrm{l} \mathrm{O}_{2} \cdot \mathrm{mmHg}^{-1} \cdot \mathrm{ml}^{-1}\right)\end{array}$ & $0.27 \pm 0.05$ & $0.26 \pm 0.06$ \\
\hline$R$ & $0.959 \pm 0.035$ & $0.958 \pm 0.038$ \\
\hline
\end{tabular}

Hemodynamics

Control CPA

CF

\begin{tabular}{lll}
$\left(\mathrm{ml} \cdot \mathrm{min}^{-1} \cdot \mathrm{g}^{-1}\right)$ & $8.36 \pm 1.25$ & $8.97 \pm 1.48$ \\
$\mathrm{CVR}$ & & \\
$\left(\mathrm{mmHg} \cdot \mathrm{ml}^{-1} \cdot \mathrm{min} \cdot \mathrm{g}^{-1}\right)$ & $4.02 \pm 1.20$ & $6.63 \pm 0.22^{\star \star}$ \\
\hline
\end{tabular}

$A$ and $B$, fitting parameters in the Eq. 1 (ESP $=$ $\left.A\left\{1-\exp \left[-B\left(V-V_{0}\right)\right]\right\}\right)$. PVA $A_{m L V}$, pressure-volume area at mean midrange left ventricular volume $(0.14 \pm 0.01 \mathrm{ml} / \mathrm{g}$; $n=12)$. $V_{0}$, volume intercept of end-systolic pressure-volume relation during different volume loading run. Slope and $\mathrm{VO}_{2}$ intercept, slope and $\mathrm{VO}_{2}$ intercept of $\mathrm{VO}_{2}$ (myocardial oxygen consumption per beat)-PVA ( $\mathrm{VO}_{2}-\mathrm{PVA}$ ) linear relations during different volume loading runs; $R$, correlation coefficients. CF, coronary flow; CVR, coronary vascular resistance. CF and CVR were measured at 3 to 6 min after the onset of short-term CPA infusion, where $V_{2}$ and $P V A_{m L V V}$ were minimum. Values are mean $\pm S D$. ${ }^{\star} p<0.05 .{ }^{*} p<0.01$.

\section{Effects of the ST and the LT CPA infusion on PVA $_{\mathrm{mLVv}}$ and $\mathrm{VO}_{2}$}

Figure 3 summarized the effects of the ST and the LT CPA infusion on $\mathrm{PVA}_{\mathrm{mLVV}}(\mathrm{A})$ and $\mathrm{VO}_{2}$ (B) data (mean $\mathrm{mLVV}, 0.15 \mathrm{ml} / \mathrm{g}$ ) (protocol $1, n=6$ ). During the ST CPA infusion, $\mathrm{PVA}_{\mathrm{mLVV}}$ and $\mathrm{VO}_{2}(p<0.01)$ were decreased by 40 and $26 \%$ of control at maximum. During the LT CPA infusion, the $\mathrm{VO}_{2}$ was increased $(p<0.05)$ almost to the control level, although $\mathrm{PVA}_{\mathrm{mLVV}}$ remained decreased significantly $(p<0.05)$ 


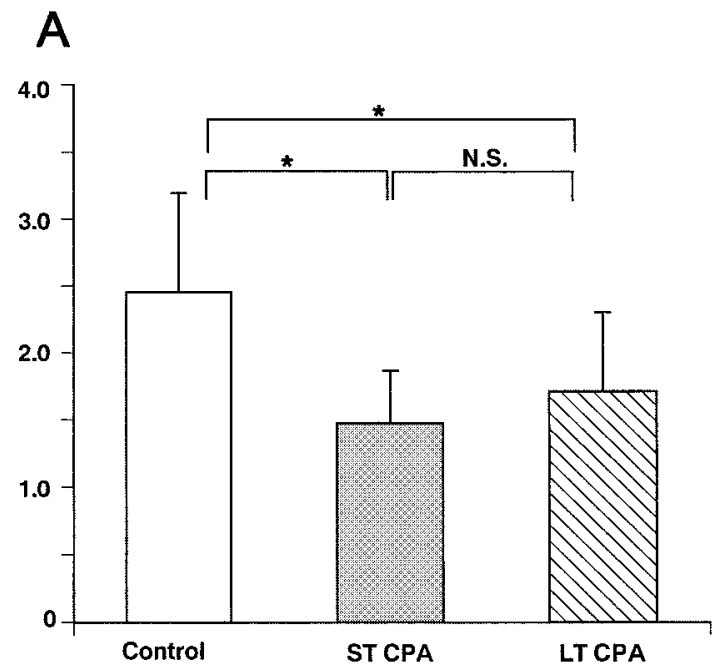

Fig. 3. Summarized data of the effect of cyclopiazonic acid (CPA, $4 \mu \mathrm{mol} / \mathrm{I}$ ) infusion on systolic pressure-volume area at midrange left ventricular volume PVA $_{m L v v}$; A) and myocardial oxygen consumption per beat $\left(\mathrm{VO}_{2}\right.$;

from the control. After washout of CPA following the $\mathrm{KCl}$-arrest, $\mathrm{VO}_{2}$ and PVA data were completely restored within 6 to $8 \mathrm{~min}$ to the control level (protocol $1, n=5)$.

Coronary vascular resistance was markedly $(p<0.01$ vs. control) increased during the ST CPA infusion (Table 1) and remained increased throughout the LT CPA infusion.

\section{Effect of $\mathrm{Ca}^{2+}$ infusion on PVA $\mathrm{mLVv}$ and $\mathrm{VO}_{2}$}

After control $\mathrm{VO}_{2}$-PVA relation was obtained, $\mathrm{ESP}_{\mathrm{mLVV}}$, and thus $\mathrm{PVA}_{\mathrm{mLVV}}$, and $\mathrm{VO}_{2}$ were gradually increased during $\mathrm{Ca}^{2+}$ intracoronary infusion at an increasing rate in steps $\left(\mathrm{Ca}^{2+}\right.$ ino-run; protocol 2$)$. We obtained a composite $\mathrm{VO}_{2}$-PVA relation line at an mLVV from these $\mathrm{PVA}_{\mathrm{mLVV}}$ and $V \mathrm{O}_{2}$ data. The parallelism of $\mathrm{VO}_{2}-\mathrm{PVA}$ relation during $\mathrm{Ca}^{2+}$ infusion to the control $\mathrm{VO}_{2}$-PVA relation was confirmed as described previously $[1,2]$. Thus in parallel to the control $V_{2}$-PVA relation line, every $V_{\mathrm{O}_{2}}$-PVA relation line during $\mathrm{Ca}^{2+}$ infusion was drawn. Consequently, the gradually increased $\mathrm{VO}_{2}$-intercept values (PVA-independent $\mathrm{VO}_{2}$ ) were obtained by this procedure [2].

\section{Oxygen costs of left ventricular contractility by $\mathrm{Ca}^{2+}$ and CPA}

We calculated the oxygen cost of left ventricular contractility [2] during intracoronary infusion with $\mathrm{Ca}^{2+}$. PVA-independent $\mathrm{VO}_{2}$ values were obtained as mentioned above. We then obtained a linear relation between PVA-independent $\mathrm{VO}_{2}$ and eEmax and the oxygen cost of LV contractility as a slope of this relation [2]. This cost indicates changes in $\mathrm{VO}_{2}$ for $\mathrm{Ca}^{2+}$

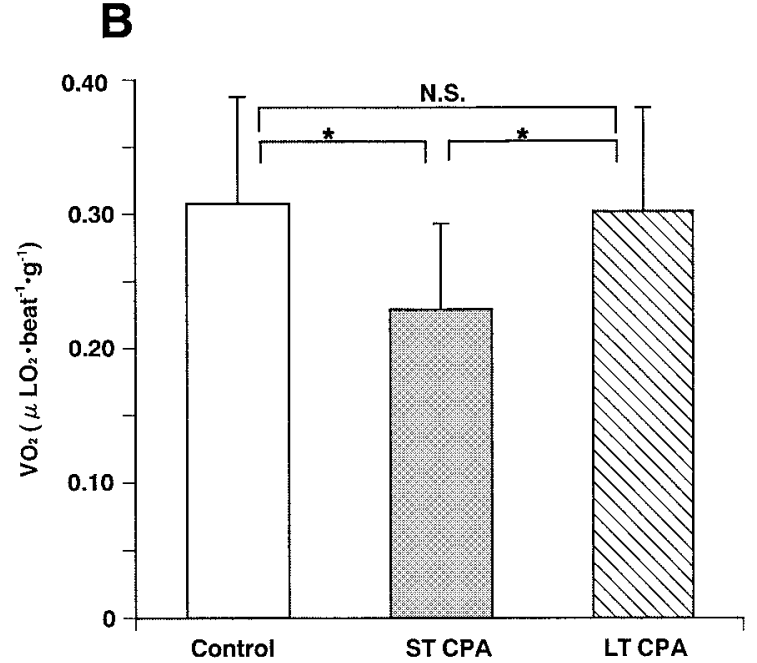

B). A: Changes in PVA $A_{m L V}$ during the short-term (ST) and the long-term (LT) CPA infusion. $\mathrm{B}$ : Changes in $\mathrm{VO}_{2}$ during the ST and the LT CPA infusion. Values are mean \pm SD. ${ }^{*} p<0.05$. N.S., not significant.

handling in the excitation-contraction coupling per unit change in left ventricular contractility by $\mathrm{Ca}^{2+}$ [2] (Fig. 4B).

During the ST and LT CPA infusion, we obtained two different $\mathrm{O}_{2}$ costs of left ventricular contractility by CPA, based on an assumption of the same slope of the $V \mathrm{O}_{2}-\mathrm{PVA}$ relations as that of the control $V_{\mathrm{O}_{2}}-\mathrm{PVA}$ relation. A representative example in the same heart as in Fig. 2 is shown in Fig. 4A. Figure 4B summarized the three different oxygen costs of left ventricular contractility. The oxygen cost during the ST CPA infusion was not significantly different from that of $\mathrm{Ca}^{2+}$, but the cost during the LT CPA infusion was 3.3 -fold higher $(p<0.05)$ than during the ST CPA infusion.

\section{Effect of DCB on increases in PVA mLvv and $\mathrm{VO}_{2}$ induced by the LT CPA infusion}

We supposed the higher oxygen cost of left ventricular contractility during the LT CPA infusion was due to the increase in $\mathrm{VO}_{2}$ for $\mathrm{Ca}^{2+}$ handling per unit change in left ventricular contractility, possibly via $\mathrm{Na}^{+} / \mathrm{Ca}^{2+}$ exchanger coupled to $\mathrm{Na}^{+} / \mathrm{K}^{+}$-ATPase. A selective blocker of $\mathrm{Na}^{+} / \mathrm{Ca}^{2+}$ exchanger, DCB ( $5 \mu \mathrm{mol} / l$ ) did not affect $\mathrm{PVA}_{\mathrm{mLVv}}$ and $V \mathrm{O}_{2}$ for at least $6 \mathrm{~min}$, whereas an $\mathrm{Na}^{+} / \mathrm{K}^{+}$-ATPase inhibitor such as ouabain might cause positive inotropic action and/or arrhythmia. We therefore investigated the effect of DCB on the increases in $\mathrm{PVA}_{\mathrm{mLVV}}$ and $V \mathrm{O}_{2}$ during the LT CPA infusion. Figure 5A and $\mathrm{B}$ shows the changes in $\mathrm{PVA}_{\mathrm{mLVV}}$ and $\mathrm{VO}_{2}$ by infusion of DCB with CPA after the LT CPA infusion (protocol 3). DCB decreased $\mathrm{PVA}_{\mathrm{mLVV}}$ by $22 \%$ and $V \mathrm{O}_{2}$ by $12 \%$, but not 
A

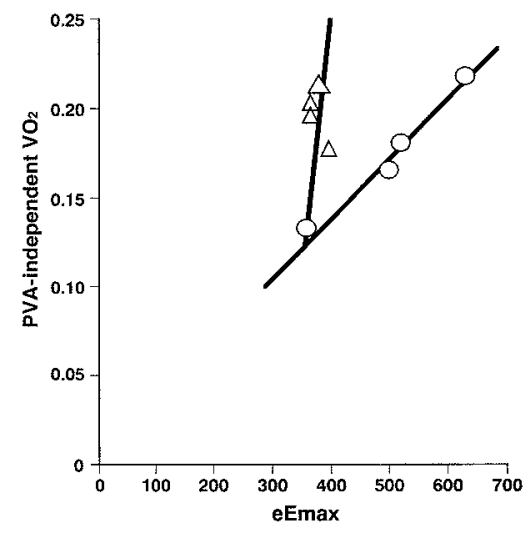

B

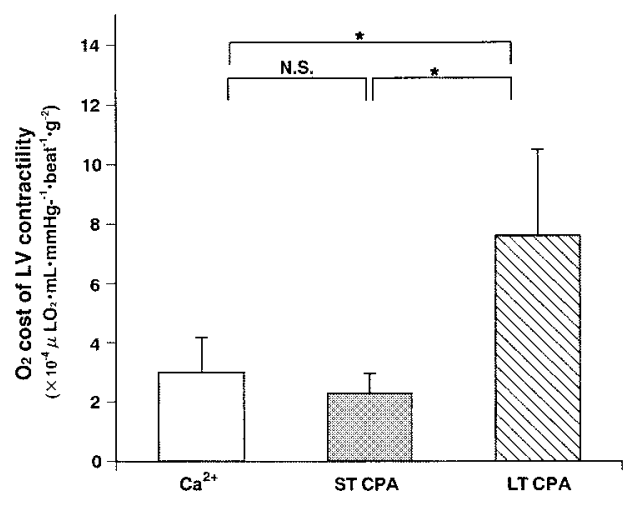

Fig. 4. A: Representative oxygen costs of left ventricular (LV) contractility during short-term (ST; open circles) and long-term (LT) CPA infusion (open triangles) in the same heart as in Fig. 2. B: Mean oxygen costs of LV contractility during $\mathrm{Ca}^{2+}$ infusion, and the ST and the LT CPA infusion. Vertical bars indicate SD. ${ }^{*} p<0.01$. N.S., not significant.

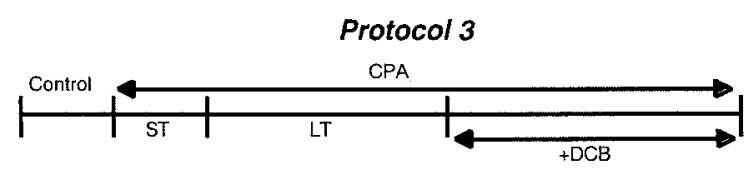

A

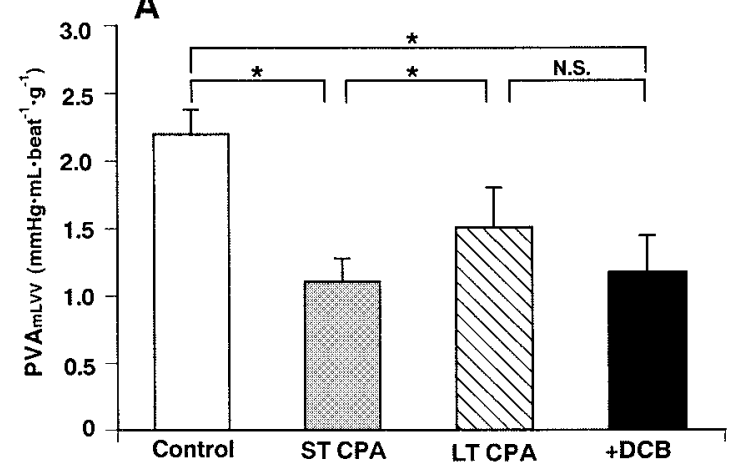

B

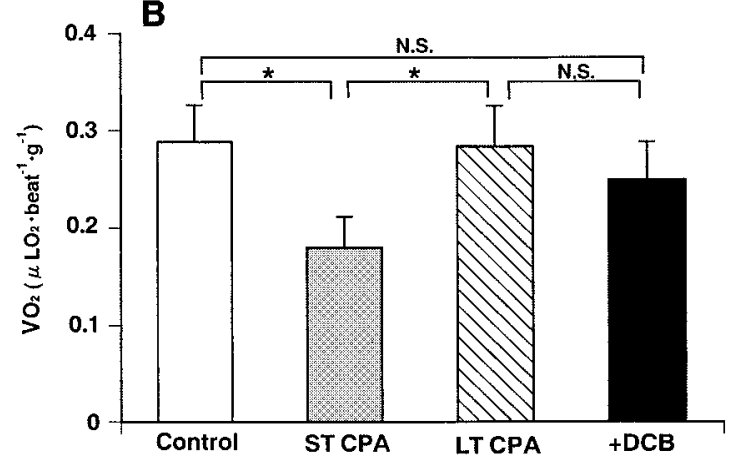

Fig. 5. Effects of $3^{\prime}, 4^{\prime}$-dichlorobenzamil (DCB, $5 \mu \mathrm{mol} / \mathrm{h}$ on increases in systolic pressure-volume area at midrange left ventricular volume (PVA $A_{m L V V}$ ) and myocardial oxygen consumption per beat $\left(\mathrm{VO}_{2}\right)$ after the long-term (LT) CPA infusion (protocol 3) and after the short-term (ST) CPA infusion (protocol 4). DCB did not

significantly. Figure 5C and D shows no significant increases in $\mathrm{PVA}_{\mathrm{mLVV}}$ and $\mathrm{VO}_{2}$ by simultaneous infusion of DCB with CPA after the ST CPA infusion (protocol 4 ), indicating that DCB completely blocked the predictable increases in $\mathrm{PVA}_{\mathrm{mLVV}}$ and $\mathrm{VO}_{2}$ during the LT CPA infusion.
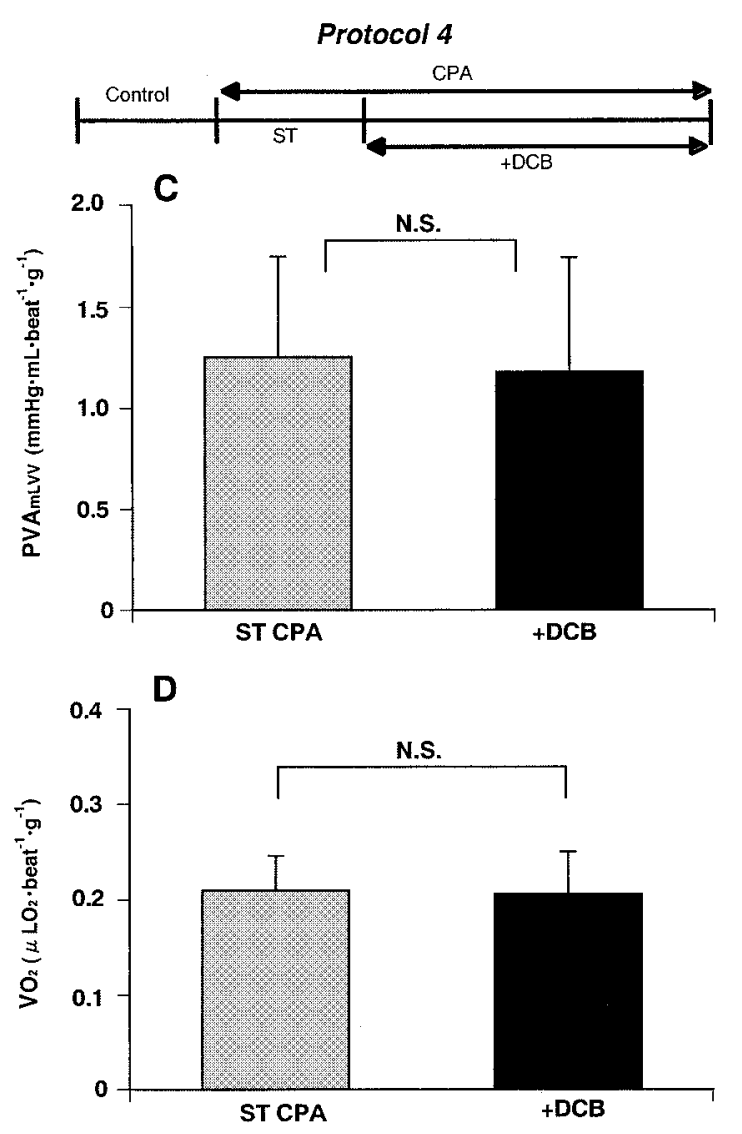

significantly decrease the already increased PVA $m L V v(A)$ and $\mathrm{VO}_{2}(\mathrm{~B})$ during the CPA infusion after the LT CPA infusion. DCB completely blocked the increases in PVA $\mathrm{mLVV}_{\mathrm{V}}(\mathrm{C})$ and $V_{\mathrm{O}_{2}}$ (D) during the LT CPA infusion. Values are mean \pm SD. ${ }^{\star} p<0.05,{ }^{* \star} p<0.01$. N.S., not significant.

\section{Basal metabolism}

Cardiac arrest was induced by $\mathrm{KCl}(0.3 \mathrm{~mol} / \mathrm{l})$ infusion ( $\mathrm{KCl}$-arrest in protocol 1), which was adjusted to abolish electrical excitation under monitoring of the ventricular epicardial electrocardiogram, but did not generate any $\mathrm{KCl}$-induced constriction of coronary vessels. $\mathrm{VO}_{2}$ data was obtained under a left ventricular 
unloading condition. Basal metabolisms in the control and during CPA infusion for $3 \mathrm{~min}$ were $18.1 \pm 6.1$ and $21.2 \pm 10.4 \mu \mathrm{O}_{2} \cdot \mathrm{min}^{-1} \cdot \mathrm{g}^{-1}$. These values were not statistically significant. This indicated that CPA did not affect the $\mathrm{VO}_{2}$ used for basal metabolism. The $\mathrm{VO}_{2}$ for excitation-contraction coupling was calculated by subtracting basal metabolic $\mathrm{VO}_{2}$ from PVA-independent $V \mathrm{O}_{2}$, showing $48.5 \pm 14.2 \mu \mathrm{O}_{2} \cdot \mathrm{min}^{-1} \cdot \mathrm{g}^{-1}$ in the control (2.5-fold $\mathrm{VO}_{2}$ of basal metabolism).

\section{DISCUSSION}

The present results demonstrated that (1) The slope and the $V \mathrm{O}_{2}$ intercept of the linear $V \mathrm{O}_{2}$ and PVA relation in the Langendorff-perfused whole heart preparation were almost similar to those reported previously in the blood-perfused whole heart preparation [1-3]. (2) The slope and the $\mathrm{VO}_{2}$ intercept of the $\mathrm{VO}_{2}-\mathrm{PVA}$ relation were unchanged during the $\mathrm{CPA}$ infusion, during which $\mathrm{VO}_{2}$ and PVA reached a steady state. (3) During the ST CPA infusion, $\mathrm{ESP}_{\mathrm{mLVv}}$ and thus $\mathrm{PVA}_{\mathrm{m}-}$ LVV were decreased by $40 \%$, and $V_{\mathrm{O}_{2}}$ was decreased by $26 \%$ at maximum. In contrast, during the LT CPA infusion, $\mathrm{PVA}_{\mathrm{mLVV}}$ was increased, and $\mathrm{VO}_{2}$ was increased toward the control; however, $\mathrm{PVA}_{\mathrm{mLVV}}$ remained significantly decreased from the control. (4) The oxygen cost of left ventricular contractility during the LT CPA infusion was significantly higher than that during the ST CPA infusion. The latter oxygen cost of left ventricular contractility was nearly equal to that by $\mathrm{Ca}^{2+}$. (5) The inhibition of $\mathrm{Na}^{+} / \mathrm{Ca}^{2+}$ exchanger with DCB did not significantly reduce the already increased $\mathrm{PVA}_{\mathrm{mLVV}}$ and $\mathrm{VO}_{2}$ during the LT CPA infusion. However, DCB completely prevented $\mathrm{PVA}_{\mathrm{mLVV}}$ and $\mathrm{VO}_{2}$ from increasing during the LT CPA infusion. All these mechanical and energetic results suggest a contribution of $\mathrm{Na}^{+} / \mathrm{Ca}^{2+}$ exchanger to extrude intracellular $\mathrm{Ca}^{2+}$ during a partial inhibition of $\mathrm{SR} \mathrm{Ca}^{2+}$ ATPase by CPA. Although the possibility that DCB inhibits $\mathrm{Na}^{+} / \mathrm{H}^{+}$exchanger cannot be excluded [13], there was no evidence showing that $\mathrm{Na}^{+} / \mathrm{H}^{+}$exchanger actually works during the LT CPA infusion. When $\mathrm{Ca}^{2+}$ extrusion by $\mathrm{Na}^{+} / \mathrm{Ca}^{2+}$ exchanger is activated during the CPA infusion, $\mathrm{Na}^{+}$influx would increase. Then $\mathrm{Na}^{+} / \mathrm{H}^{+}$exchanger may work and induce $\mathrm{H}^{+}$influx (acidosis). If so, however, no increase in $\mathrm{PVA}_{\mathrm{mLVV}}$ or $V \mathrm{O}_{2}$ will be found.

$\mathrm{Ca}^{2+}$ handling mechanisms work in the balance between $\mathrm{Ca}^{2+}$ uptake by SR and $\mathrm{Ca}^{2+}$ extrusion by $\mathrm{Na}^{+} / \mathrm{Ca}^{2+}$ exchanger. $\mathrm{Ca}^{2+}$ extrusion mechanisms via $\mathrm{Na}^{+} / \mathrm{Ca}^{2+}$ exchanger coupled to $\mathrm{Na}^{+} / \mathrm{K}^{+}$-ATPase are energetically more wasteful than SR $\mathrm{Ca}^{2+}$-ATPase (1 $\mathrm{Ca}^{2+}: 1$ ATP vs. $2 \mathrm{Ca}^{2+}: 1$ ATP). The oxygen cost of left ventricular contractility indicates changes in $\mathrm{VO}_{2}$ for $\mathrm{Ca}^{2+}$ handling in the excitation-contraction coupling per unit change in left ventricular contractility. If $\mathrm{Ca}^{2+}$ recirculation fraction via uptake by $\mathrm{SR}$ would decrease and $\mathrm{Ca}^{2+}$ extrusion mechanisms via $\mathrm{Na}^{+} / \mathrm{Ca}^{2+}$ exchanger would increase under the constant left ventricular contractility, this oxygen cost would be higher. This speculation is supported by the results shown in Fig. 4.

In rat normal myocardium, $\mathrm{Ca}^{2+}$ recirculation fraction mediated via SR was high, as previously reported to be 0.7 to 0.8 in papillary muscles [16]. The $\mathrm{Ca}^{2+}$ handling $\mathrm{VO}_{2}$ in rat myocardial slices was decreased to $70 \%$ of control by treatment with CPA [6], suggesting that CPA-sensitive $\mathrm{VO}_{2}$ component reflects $\mathrm{Ca}^{2+}$ recirculation fraction [7]. Therefore a complete blockade of SR $\mathrm{Ca}^{2+}$-ATPase would be expected to decrease the PVA-independent $\mathrm{VO}_{2}$ by $70 \%$ of control.

However, CPA decreased $\mathrm{PVA}_{\mathrm{mLVv}}$ by $40 \%$ and $\mathrm{VO}_{2}$ by $26 \%$ at maximum during the ST infusion. It has been reported that the depression of $\mathrm{Ca}^{2+}$ uptake via SR is incomplete even by higher concentrations of CPA in multicellular preparations such as rabbit papillary muscles or ventricular trabeculae [17]. The concentration of CPA used in the present study was low $(4 \mu \mathrm{mol} / l)$. Therefore it seems very likely that the depression of $\mathrm{Ca}^{2+}$ uptake by SR at the present low concentration of CPA is incomplete. Even under this condition, during the LT CPA infusion the balance of $\mathrm{Ca}^{2+}$ fluxes shifts in favor of $\mathrm{Ca}^{2+}$ extrusion by the $\mathrm{Na}^{+} / \mathrm{Ca}^{2+}$ exchanger, thereby increasing $\mathrm{VO}_{2}$ toward the control level.

Furthermore, $\mathrm{Ca}^{2+}$ uptaken by SR and thus $\mathrm{Ca}^{2+}$ induced $\mathrm{Ca}^{2+}$ release seems to be "partially" recovered during the LT infusion because of a partial inhibition of SR $\mathrm{Ca}^{2+}$-ATPase by CPA, thereby increasing $\mathrm{PVA}_{\mathrm{mLVv}}$. This recovery seems to be triggered by the activation of $\mathrm{Ca}^{2+}$ extrusion by the $\mathrm{Na}^{+} / \mathrm{Ca}^{2+}$ exchanger, although the detailed mechanisms remain unknown. This speculation is supported by the results showing that the increased $\mathrm{PVA}_{\mathrm{mLVV}}$ remained to be significantly reduced from the control and the pretreatment of DCB abolished the increase in $\mathrm{PVA}_{\mathrm{mLVV}}$.

It has been reported that the induction of heart failure triggers a shift in the balance of cytosolic $\mathrm{Ca}^{2+}$ extrusion mechanisms from SR $\mathrm{Ca}^{2+}$ uptake toward transsarcolemmal $\mathrm{Ca}^{2+}$ removal $[18,19]$. The present heart briefly treated with low concentration of CPA could simulate the cardiac systolic dysfunction with wasteful $\mathrm{Ca}^{2+}$ handling $\mathrm{VO}_{2}$.

CPA produced a negative inotropic effect in adult rat myocardium through the inhibition of SR function [20]. In contrast, CPA had minimum effects on neona- 
tal rat myocardium [20]. In neonatal myocardium, SR plays a much smaller role for $\mathrm{Ca}^{2+}$ handling in excitation-contraction coupling [21]. Therefore the present heart briefly treated with a low concentration of CPA mimicks a "hybrid" of neonatal and adult rat myocardium.

In the present study, we measured coronary perfusion pressure. As reported previously [22], we observed the increased coronary vascular resistance throughout the ST and LT CPA infusion at constant perfusion rate, although its underlying mechanisms were unknown.

\section{CONCLUSION}

The present results, for the first time, revealed the initial decrease and the following increase in oxygen consumption for $\mathrm{Ca}^{2+}$ handling in the excitation-contraction coupling and systolic pressure-volume area (PVA) during the application of a low concentration of an inhibitor of sarcoplasmic reticulum $\mathrm{Ca}^{2+}$-ATPase, cyclopiazonic acid (CPA), in terms of rat left ventricular mechanoenergetics. During the latter phase, the oxygen cost of left ventricular contractility was higher than that during the former phase. Pretreatment with a $\mathrm{Na}^{+} / \mathrm{Ca}^{2+}$ exchanger inhibitor, 3',4'-dichlorobenzamil, blocked the latter phase during the application of CPA, indicating the contribution of $\mathrm{Na}^{+} / \mathrm{Ca}^{2+}$ exchanger to increases in the oxygen consumption and PVA. This result suggested the possibility for the contribution of greater energy-wasting $\mathrm{Ca}^{2+}$ extrusion processes (such as $\mathrm{Na}^{+} / \mathrm{K}^{+}$-ATPase coupled to the $\mathrm{Na}^{+} / \mathrm{Ca}^{2+}$ exchanger; its stoichiometry is 1 ATP : 1 $\mathrm{Ca}^{2+}$ ) to the higher oxygen cost of LV contractility.

This study was partly supported by a Grant-in-Aid for Scientific Research (11470277) from the Ministry of Education, Science, Sports and Culture of Japan.

\section{REFERENCES}

1. Hata $Y$, Sakamoto T, Hosogi $S$, Ohe $T$, Suga $H$, and Takaki M: Linear $\mathrm{O}_{2}$ use-pressure-volume area relation from curved end-systolic pressure-volume relation of the blood-perfused rat left ventricle. Jpn J Physiol 48: 197-204, 1998

2. Tsuji T, Ohga Y, Yoshikawa Y, Sakata S, Kohzuki H, Misawa H, Abe T, Tabayashi N, Kobayashi S, Kitamura S, Taniguchi S, Suga H, and Takaki M: New index for oxygen cost of contractility from curved end-systolic pressure-volume relations in cross-circulated rat hearts. Jpn J Physiol 49: 513-520, 1999

3. Hata $Y$, Sakamoto T, Hosogi S, Ohe T, Suga H, and Takaki M: Effects of thapsigargin and $\mathrm{KCl}$ on the $\mathrm{O}_{2}$ use of the excised blood-perfused rat heart. J Mol Cell Cardiol 30: 2137-2143, 1998
4. Fujii W, Takaki $M$, Yoshida $A$, Ishidate $H$, Ito $H$, and Suga $\mathrm{H}$ : Effect of intracoronary caffeine on left ventricular mechanoenergetics in $\mathrm{Ca}^{2+}$ overload failing rat hearts. Jpn J Physiol 48: 373-381, 1998

5. Suga H: Ventricular energetics. Physiol Rev 70: 247-277, 1990

6. Takaki M, Kohzuki H, Kawatani Y, Yoshida A, Ishidate $\mathrm{H}$, and Suga $\mathrm{H}$ : Sarcoplasmic reticulum $\mathrm{Ca}^{2+}$ pump blockade decreases $\mathrm{O}_{2}$ use of unloaded contracting rat heart slices: thapsigargin and cyclopiazonic acid. J Mol Cell Cardiol 30: 649-659, 1998

7. Ásgrimsson HJ, Wohlfart B, Brandt J, and Johannsson $\mathrm{M}$ : Effects of $\left[\mathrm{Na}^{+}\right]_{0},\left[\mathrm{Ca}^{2+}\right]_{0}$ and cyclopiazonic acid on decline of post-extrasystolic potentiation and twitch kinetics in guinea-pig and human myocardial preparations. Acta Physiol Scand 166: 195-201, 1999

8. Banijamali HS, Gao W-D, Macintosh BR, and ter Keurs HEDJ: Force-interval relations of twitches and cold contractures in rat cardiac trabeculae. Effect of ryanodine. Circ Res 69: 937-948, 1991

9. Trafford AW, Diaz ME, Negretti N, and Eisner DA: Enhanced $\mathrm{Ca}^{2+}$ current and decreased $\mathrm{Ca}^{2+}$ efflux restore sarcoplasmic reticulum $\mathrm{Ca}^{2+}$ content after depletion. Circ Res 81: 477-484, 1997

10. Trafford AW, Diaz ME, Sibbring GC, and Eisner DA: Modulation of CICR has no maintained effect on systolic $\mathrm{Ca}^{2+}$ : simultaneous measurements of sarcoplasmic reticulum and sarcolemmal $\mathrm{Ca}^{2+}$ fluxes in rat ventricular myocytes. J Physiol (Lond) 522: 259-270, 2000

11. Takahashi S, Kato $Y$, Adachi M, Agata N, Tanaka H, and Shigenobu K: Effects of cyclopiazonic acid on rat myocardium: inhibition of calcium uptake into sarcoplasmic reticulum. J Pharmacol Exp Ther 272: 1095-1100, 1995

12. Siegl PKS, Cragoe EJ Jr, Trumble MJ, and Kaczorowski GJ: Inhibition of $\mathrm{Na}^{+} / \mathrm{Ca}^{2+}$ exchanger in membrane vesicle and papillary muscle preparations from guinea pig heart by analogs of amiloride. Proc Natl Acad Sci USA 81: 3238-3242, 1984

13. Blaustein MP and Lederer WJ: Sodium/calcium exchange: its physiological implications. Physiol Rev 79: 763-854, 1999

14. Wannenburg T, Schulman SP, and Burkhoff D: End-systolic pressure-volume and $\mathrm{MVO}_{2}$-pressure-volume area relations of isolated rat hearts. Am J Physiol 262: H1287-H1293, 1992

15. Kuwabara M, Takenaka H, Maruyama H, Onitsuka T, and Hamada M: Effect of prolonged hypothermic ischemia and reperfusion on oxygen consumption and total mechanical energy in rat myocardium. Transplantation 64: 577-583, 1997

16. Ragnarsdóttir $\mathrm{K}$, Wohlfart $\mathrm{B}$, and Jóhannsson M: Mechanical restitution of the rat papillary muscle. Acta Physiol Scand 115: 183-191, 1982

17. Baudet S, Shaoulian R, and Bers DM: Effects of thapsigargin and cyclopiazonic acid on twitch force and sarcoplasmic reticulum $\mathrm{Ca}^{2+}$ content of rabbit ventricular muscle. Circ Res 73: 813-819, 1993

18. Winslow R, Rice J, Jafri S, Marbán E, and O'Rourke B: Mechanisms of altered excitation-contraction coupling in canine tachycardia-induced heart failure, II Model studies. Circ Res 84: 571-586, 1999 


\section{H. MISAWA et al.}

19. O'Rourke B, Kass DA, Tomaselli GF, Kääb S, Tunin R, and Marbán E: Mechanisms of altered excitation-contraction coupling in canine tachycardia-induced heart failure, I Experimental studies. Circ Res 84: 562-570, 1999

20. Agata N, Tanaka H, and Shigenobu K: Possible action of cyclopiazonic acid on myocardial sarcoplasmic reticulum: inotropic effects on neonetal and adult rat heart. Br J Pharmacol 108: 571-572, 1993

21. Tanaka $\mathrm{H}$ and Shigenobu $\mathrm{K}$ : Effect of ryanodine on neonatal and adult rat heart: developmental increase in sarcoplasmic reticulum function. J Moll Cell Cardiol 21: 1305-1313, 1989

22. Khandoudi N, Percevault-Albadine J, and Bril A: Consequences of the inhibition of the sarcoplasmic reticulum calcium ATPase on cardiac function and coronary flow in rabbit isolated perfused heart: role of calcium and nitric oxide. J Moll Cell Cardiol 30: 1967-1977, 1998 